\title{
Raman Microanalysis of Meteorites and Other Geological Samples
}

\author{
Thomas J Tague Jr. and Peng Wang
}

Bruker Optics, Inc., 19 Fortune Drive, Billerica, MA 01821

The Raman analysis of meteorites has been of growing interest in recent years. The study of meteorites allows for a comparison between terrestrial igneous rocks and rocks of extraterrestrial origin. Meteorites fall into four categories, Shergottites, Nakhlites, Chassignites, (SNC) and orthopyroxenites. Evidence suggests that SNC meteorites may provide a glimpse into Martian history and more particularly, whether life existed on Mars. Raman microanalysis is highly specific and provides access to lower wavelength vibrational modes typically challenging to access by FTIR. Raman microanalysis is nondestructive and is capable of confocal depth analysis. The spot size of the excitation laser beam can be submicron allowing the analysis of individual grains. The data was collected for 10 seconds using a $100 x$ objective (0.9NA) resulting in a 1 micron spot size with the $785 \mathrm{~nm}$ excitation laser. For grating based Raman systems, the spectral resolution varies as a function of wavelength and averaged $3 \mathrm{~cm}^{-1}$. The excitation laser was run at $1 \mathrm{~mW}$ to prevent damage to the meteorite or the inducement of phase changes that can frequently occur in geological samples. Magnetite is particularly sensitive to undergoing a phase transition to haematite with $785 \mathrm{~nm}$ excitation.

Figure 1 shows the optical images collected from the meteorite. The Raman spectrum was collected from the area in the center of the micrographs and allows for the definitive identification of Olivine (SiO4) ( area of the meteorite that is identified as Clinopyroxene (major bands at 1010 and $668 \mathrm{~cm}^{-1}$, minor band at $322 \mathrm{~cm}^{-1}$ ). The position of the $668 \mathrm{~cm}^{-1}$ band is specific in differentiating lunar and Martian meteorites. The $668 \mathrm{~cm}^{-1}$ band is typically red shifted by several in lunar meteorites. Additionally, the presence of Maskelynite (bands at 512 and $1000 \mathrm{~cm}^{-1}$ ) was detected by its Raman spectrum indicating that the rock was shocked ${ }^{\text {ii }}$ There was little rare earth fluorescence under ultraviolet illumination indicating that the meteorite was not rich in phosphorus or other fluorescing trace compounds. Siderite $\left(\mathrm{FeCO}_{3}\right)$ (bands 293, 730, and $1084 \mathrm{~cm}^{-1}$ ) and Magnetite $\left(\mathrm{Fe}_{3} \mathrm{O}_{4}\right.$ ) (bands at 304, 540, and $667 \mathrm{~cm}^{-1}$ ) were also detected and identified by their Raman signature. 


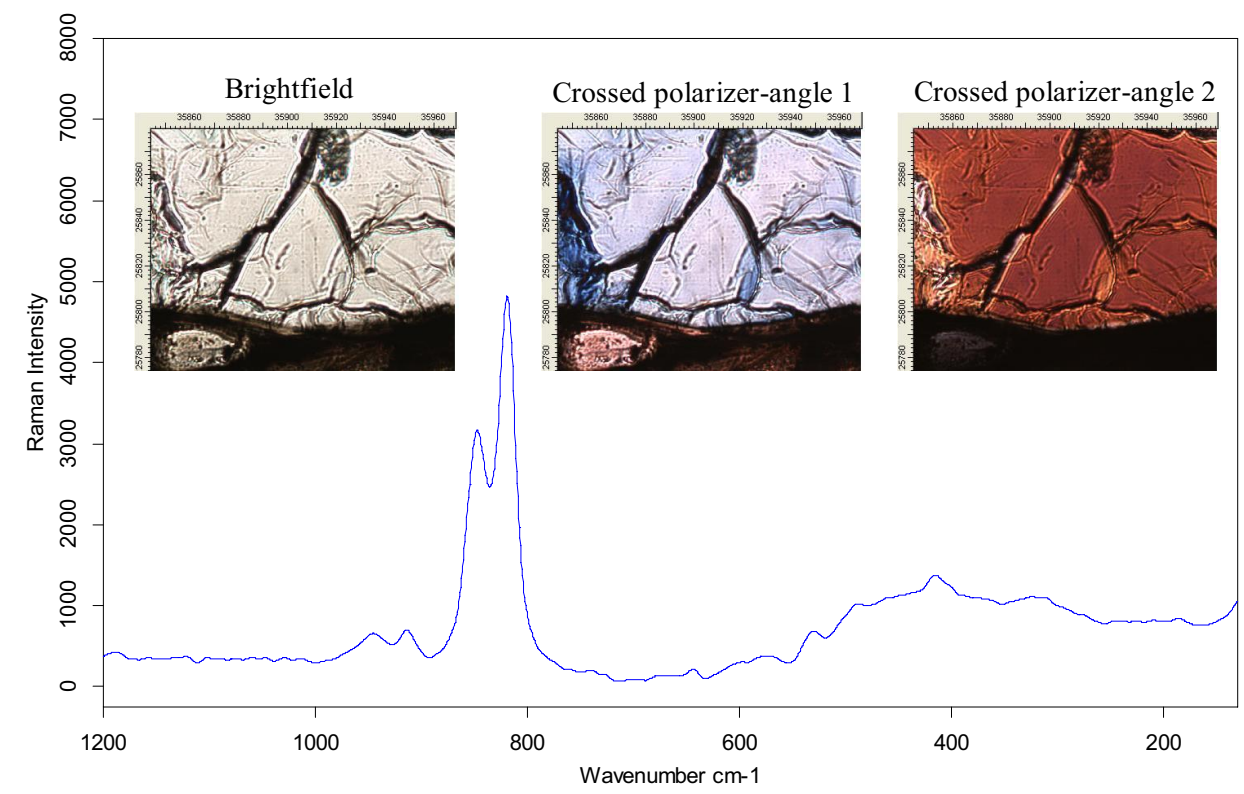

Figure 1 - Brightfield and polarized light images of a meteorite section with the resultant Raman spectrum, identified as Olivine, shown below.

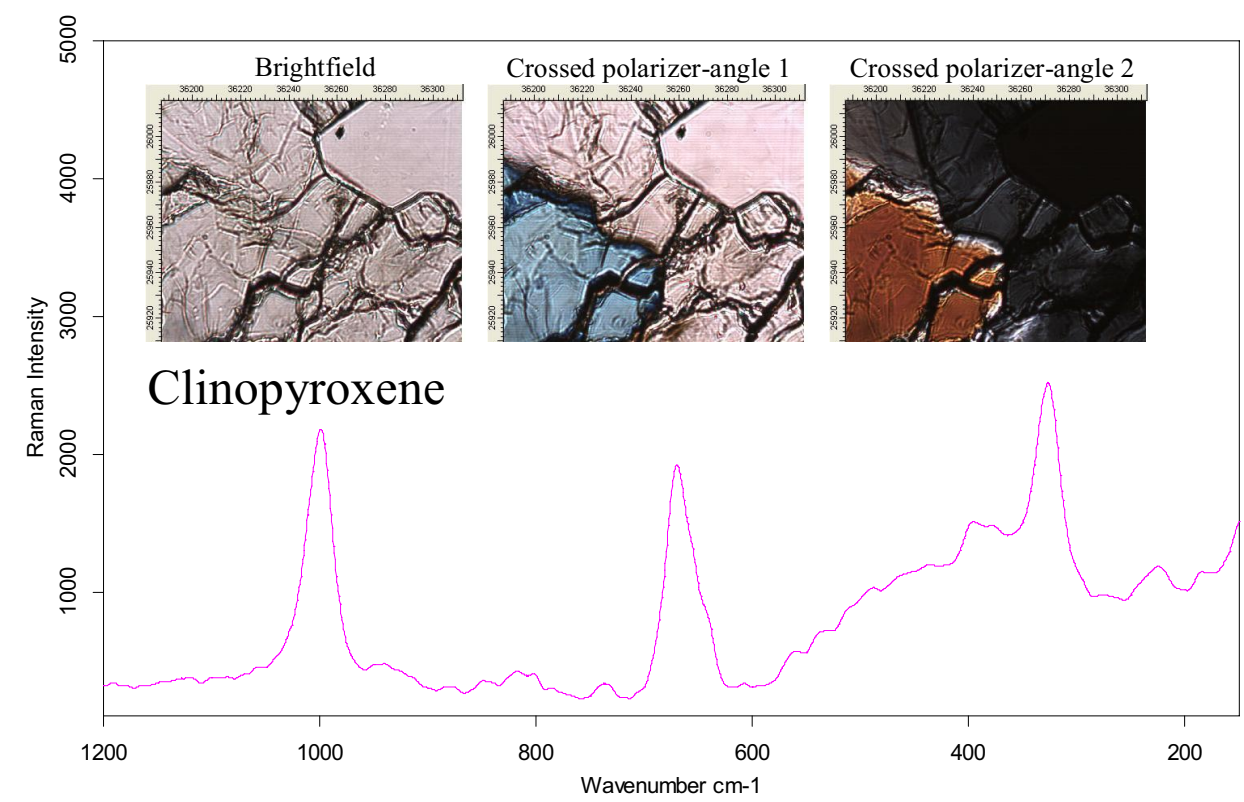

Figure 2 - Brightfield and polarized light images of a meteorite section with the resultant Raman spectrum, identified as Clinopyroxene, shown below.

${ }^{i}$ F. Rull, J. Martinez-Frias, A. Sansano, J. Medina, and H.G.M. Edwards, J. Raman Spectrosc. 2004; 35, 497-503.

${ }^{i i}$ A. Wang, B. L. Joliff, A. Haskin, Lunar Planetary Science XXIX, 1523. 